\title{
L-Tyrosine-loaded nanoparticles increase the antitumoral activity of direct electric current in a metastatic melanoma cell model
}

This article was published in the following Dove Press journal:

International Journal of Nanomedicine

12 November 2010

Number of times this article has been viewed

\author{
Vânia Emerich Bucco \\ de Campos' \\ Cesar Augusto Antunes \\ Teixeira' \\ Venicio Feo da Veiga ${ }^{2}$ \\ Eduardo Ricci Júnior' \\ Carla Holandino' \\ 'Departamento de Medicamentos, \\ Faculdade de Farmácia, ${ }^{2}$ Instituto \\ de Microbiologia Professor \\ Paulo de Góes, Universidade \\ Federal do Rio de Janeiro, Rio \\ de Janeiro, Brazil
}

\begin{abstract}
Inhibition of tumor growth induced by treatment with direct electric current (DC) has been reported in several models. One of the mechanisms responsible for the antitumoral activity of DC is the generation of oxidative species, known as chloramines. With the aim of increasing chloramine production in the electrolytic medium and optimizing the antitumoral effects of DC, poly( $\varepsilon$-caprolactone) (PCL) nanoparticles (NPs) loaded with the amino acid tyrosine were obtained. The physical-chemical characterization showed that the NPs presented size in nanometric range and monomodal distribution. A slightly negative electrokinetic potential was also found in both blank NPs and L-tyrosine-loaded PCL NPs. The yield of the loading process was approximately $50 \%$. Within $3 \mathrm{~h}$ of dissolution assay, a burst release of about $80 \% \mathrm{~L}$-tyrosine was obtained. The in vitro cytotoxicity of DC was significantly increased when associated with L-tyrosine-loaded NPs, using a murine multidrug-resistant melanoma cell line model. This study showed that the use of the combination of nanotechnology and DC has a promising antineoplastic potential and opens a new perspective in cancer therapy.
\end{abstract}

Keywords: direct electric current, nanotechnology, cancer therapy, L-tyrosine, B16F10 cells

\section{Introduction}

Nanoparticulate systems show promise as active vectors because of their capacity to release substances. ${ }^{1}$ The advantages of using this approach for drug delivery result from some interesting properties of these systems. Because of their small size, they can travel through the endothelium of inflammatory sites, epithelium (eg, intestinal tract and liver), and tumors or penetrate microcapillaries. ${ }^{2}$ In addition to their biodegradability and biocompatibility, the use of these delivery systems result in increased bioavailability of transported drugs with minimal toxicity. ${ }^{3,4}$ Nanoparticle (NP) systems have recently been incorporated within cancer therapies, because of their ability to concentrate drugs at the tumor site, which enhances their cytotoxic effects on the cancer cells and therefore reduces systemic side effects..$^{5-7}$

Poly ( $\varepsilon$-caprolactone) (PCL) is an aliphatic polyester that is used to develop injectable sustained delivery systems, such as polymeric NPs. ${ }^{8}$ PCL NPs have been used as drug-carrier systems for amphotericin B, ${ }^{9,10}$ indomethacin, ${ }^{11}$ griseofulvin, ${ }^{12}$ tamoxifen, ${ }^{13}$ vaccines,${ }^{14}$ magnetic composites,${ }^{15}$ and cyclosporine A. ${ }^{16}$ PCL NP production by the double emulsion solvent evaporation method (DEEM) has been shown to exhibit satisfactory encapsulation efficiency for hydrophilic drugs. ${ }^{17-19}$

Scientific investigations have demonstrated that electrotherapy (EChT) presents an effective approach for treating several types of cancer ${ }^{20-22}$ EChT uses a low direct electric current (DC) to treat tumor tissue through two or more electrodes placed 
within the tumoral zone or within its surrounding area. This treatment is noted for its significant effectiveness, minimal invasiveness, localized action, and low cost. ${ }^{23-25}$ Nordenström discussed the mechanisms associated with this therapy, such as $\mathrm{pH}$ alterations, electroosmotic transport of water, and the effects on ionic transmembrane flow, as partially responsible for the efficacy of EChT. ${ }^{26,27}$

An important milestone for the study of EChT was the development of an in vitro experimental model for investigation of DC effects on culture cell lines. ${ }^{28-30}$ Using this model, Veiga et al showed that DC can destroy tumor cells via two distinct mechanisms: apoptosis and necrosis. ${ }^{30}$ Both aforementioned mechanisms appear to be associated with the DC polarity: cells exposed to anodic flow (AF) undergo mostly apoptosis, whereas those exposed to cathodic flow (CF) die almost entirely as a result of necrosis. ${ }^{30}$ These authors attributed the apoptotic cell death to chlorinated species $\left(\mathrm{Cl}^{-}, \mathrm{Cl}_{2}, \mathrm{HOCl}\right)$ generated by $\mathrm{AF}$, which react with amino acids to produce oxidizing and apoptosis-inducing molecules called chloramines. As a matter of fact, other studies developed using different reactive oxygen species have proven that oxidants, hypochlorous acid and chloramines, induced apoptotic cell death from the reaction of chlorinated species with free amino acids present in the cell suspension. ${ }^{31,32}$ Englert and Shacter ${ }^{32}$ compared the influence of different amino acids (taurine, arginine, lysine, glutamic acid, glutamine, and isoleucine) on the viability of lymphoma cells in the presence of oxidant compounds. These authors showed that depending on the kind of amino acids, cell death by necrosis or apoptosis was detected in the cellular medium. In their experimental model, the formation of chloramines generated by the reaction of $\mathrm{H}_{2} \mathrm{O}_{2}$ with glutamine and arginine induced exclusively apoptosis and necrosis, respectively. ${ }^{32}$ Indeed, Veiga et al confirmed this hypothesis by adding L-glutamine to the electrolytic medium during exposure of human leukemic cells to AF generated by DC. ${ }^{30}$ Besides, L-tyrosine, L-glutamine, and L-tryptophan were also tested in B16F10 murine melanoma cells, and the highest cytotoxic effects induced by chloramines generated by DC stimulation were obtained in the presence of L-tyrosine (unpublished data). Considering this preliminary screening, L-tyrosine was the amino acid chosen for the present study.

Given the results of these previous works, it is likely that amino acid encapsulation within NPs may modulate chloramine production within the AF and, most importantly, increase its delivery to target cells. Targeted drug delivery would enhance the damage induced by these molecules and thus improves DC antitumoral activity. To verify this hypothesis, the present work describes the use of nanotechnology in association with DC for the first time. L-Tyrosine was loaded onto PCL polymer, and the physical and chemical parameters of this loading process were determined. Additionally, the cytotoxicity of this association was evaluated in murine multidrug-resistant melanoma cell line B16F10. Our results show that the use of nanotechnology along with DC has a promising antineoplastic potential.

\section{Material and methods Chemicals}

The following chemicals were purchased from VETEC Química Fina (Rio de Janeiro, Brazil): polyvinyl alcohol (PVA), trypan blue powder, dichloromethane (DCM), L-tyrosine, monobasic sodium phosphate, dibasic potassium phosphate, and sodium chloride. The following cell culture items were purchased from Gibco Invitrogen Corporation (New York, NY): Dulbecco's modified Eagle's medium (DMEM), glutamine, fetal bovine serum (FBS), sodium bicarbonate, sodium hydroxide, Pen Strep (penicillin 10,000 units $/ \mathrm{mL}+$ streptomycin $10,000 \mu \mathrm{g} / \mathrm{mL}$ aqueous solution), and trypsin 1:250 powder. Finally, these items were purchased from Sigma-Aldrich (St Louis, MO): dimethyl sulfoxide, ethylenediaminetetraacetic acid, $N$-2hydroxyethylpiperazine- $N^{\prime}$-2-ethanesulfonic acid, [3-(4,5dimethylthiazol-2-yl)-2,5-diphenyltetrazolium bromide] (MTT), and PCL.

\section{Nanoparticle preparation}

PCL NPs containing L-tyrosine were prepared by the double emulsification evaporation method. One hundred milligrams of PCL was briefly dissolved in $5 \mathrm{~mL}$ of DCM. This organic solution was emulsified in $1 \mathrm{~mL}$ of $1 \%$ PVA with $0.4 \mathrm{mg} / \mathrm{mL}$ of L-tyrosine aqueous internal phase for 1 min using an ultrasonicator (Ultrasonic Processor - UP $100 \mathrm{H}, 60 \mathrm{~W}$, $30 \mathrm{kHz}$; Hielscher, Germany) in an ice bath. This primary emulsion was poured into $20 \mathrm{~mL}$ of a $0.5 \%$ PVA aqueous solution and sonicated again with the same ultrasonic probe for 2 min under the same conditions to create the water for oil-in-water emulsion. The solvent (DCM) was evaporated with stirring at room temperature $\left(28^{\circ} \mathrm{C}\right)$. NPs suspensions were purified twice by a 30-min centrifugation at 10,000 $\times g$ (Avanti J-2 cooled ultracentrifuge; Beckman Coulter, San Francisco, CA) for $40 \mathrm{~min}$ and followed by resuspension in $4 \mathrm{~mL}$ of distilled water. ${ }^{33-35}$

The suspension was transferred into a glass vial and stored at $-20^{\circ} \mathrm{C}$. Freeze-drying was carried out in a lyophilizer (freeze dry system; Labconco, Brazil) and yielded powdered NPs. 
The samples were stored at room temperature $\left(28^{\circ} \mathrm{C}\right)$ before analysis. The lyophilized samples were resuspended in water and observed by optical microscopy to detect the presence of aggregates. ${ }^{36}$

The process yield was calculated using Eq. 1:

$$
Y(\%)=\left(\frac{M_{\mathrm{NP}}}{M_{\mathrm{T}}}\right) \times 100,
$$

where $Y(\%)$ is the process yield, $M_{\mathrm{NP}}$ is the mass of NPs recovered after freeze-drying, and $M_{\mathrm{T}}$ is the mass of polymer plus the mass of L-tyrosine in formulation before the process. The encapsulation method was performed in triplicate $(n=3)$.

The NPs encapsulation efficiency was determined by a spectrophotometric method. The drug was dissolved in phosphate-buffered saline $\left(\mathrm{PBS}, \mathrm{g} / \mathrm{L}: 0.26 \mathrm{KH}_{2} \mathrm{PO}_{4}\right.$, $\left.2.17 \mathrm{Na}_{2} \mathrm{HPO}_{4} \cdot 7 \mathrm{H}_{2} \mathrm{O}, 8.71 \mathrm{NaCl}\right)$, and the absorbance was measured at $275 \mathrm{~nm}$ (spectrophotometer; UV $2401 \mathrm{PC}$; Shimadzu Kyoto, Japan). The calibration curve was linear $(r=0.999)$ for L-tyrosine in a range of 20-200 $\mu \mathrm{g} / \mathrm{mL}$. Drug concentrations were calculated based on the standard curve equation. Ten milligrams of freeze-dried NPs was dissolved in $5 \mathrm{~mL}$ of DCM to dissolve the polymer, and $5 \mathrm{~mL}$ of PBS was added to preferentially precipitate the polymer. The suspension was filtered through a membrane filter $(0.22 \mu \mathrm{m}$; Millex, The Netherlands) to remove the insoluble polymer and rediluted with PBS for analysis via the spectrophotometric method as described above. Encapsulation efficiency was calculated from Eq. 2:

$$
\mathrm{EE}=\left(\frac{M_{1}}{M_{2}}\right) \times 100,
$$

where EE is the encapsulation efficiency, $M_{1}$ is the mass of L-tyrosine $(\mu \mathrm{g})$ on the NPs, and $M_{2}$ is the mass of L-PCL (mg). The experiments were performed in triplicate $(n=3)$.

NPs were characterized by size, polydispersity index (PI), and electric potential (zeta potential). The size and PI of the particles were determined by photon correlation spectroscopy using a Zetasizer ${ }^{\circledR} 3000$ (Malvern Instruments, Worcestershire, UK) with a laser reader of $633 \mathrm{~nm}$, operated at an angle of $173^{\circ}$, and a temperature of $25^{\circ} \mathrm{C}$. The samples of L-tyrosine-loaded and unloaded PCL NPs were diluted: $1: 400(\mathrm{p} / \mathrm{v})$ in distilled water, and $1 \mathrm{~mL}$ of this solution was added to a plastic cuvette. The zeta potential was measured in a $10^{-3} \mathrm{M} \mathrm{NaCl}$ aqueous solution using the electrophoretic mode of the device. ${ }^{35}$ Each sample was measured in triplicate for each parameter.
NPs morphology was studied by transmission electron microscopy (Morgagni 268; FEI Company, Eindhoven, The Netherlands). The sample preparation was performed from an aqueous suspension containing $50 \mathrm{mg}$ of NPs in $20 \mathrm{~mL}$ of distilled water, and $10 \mu \mathrm{L}$ of this suspension was placed on a carbon-coated electron microscopy grid following fixation with $10 \mu \mathrm{L}$ of uranyl acetate $3 \%(\mathrm{w} / \mathrm{v})$ for $1 \mathrm{~min}$. The grid was properly dried and then examined using transmission electron microscope. ${ }^{36}$

The release profile of L-tyrosine-loaded PCL NPs was assessed by a dissolution study with spectrophotometric analysis. ${ }^{34}$ A 50-mg sample of NPs loaded with approximately $1.46 \mathrm{mg}$ of L-tyrosine was resuspended in $10 \mathrm{~mL}$ of PBS, and this suspension was stirred at $200 \mathrm{rpm}$ and $37^{\circ} \mathrm{C}$. At time points of $1,2,3,24,48,72$, and $96 \mathrm{~h}$, the entire content was withdrawn and centrifuged at $10,000 \mathrm{rpm}$ for $30 \mathrm{~min}$. The supernatant was collected and filtered with a $0.22-\mu \mathrm{m}$ cellulose nitrate membrane; the L-tyrosine concentration was determined by spectrophotometry at a wavelength of $275 \mathrm{~nm}$ (spectrophotometer, UV 2401 PC; Shimadzu). The remaining NPs precipitate was resuspended in $10 \mathrm{~mL}$ of PBS and returned to stirring at $37^{\circ} \mathrm{C}$ until the next sampling time.

\section{Cell culture}

B16F10 cells were obtained from Rio de Janeiro's Cell Bank (UFRJ, Brazil). They were cultured at $37^{\circ} \mathrm{C}$ in $25-\mathrm{cm}^{2}$ culture flasks containing DMEM medium supplemented with $10 \%(\mathrm{v} / \mathrm{v})$ FBS. $\mathrm{pH}$ was controlled by the addition of $3 \mathrm{~g} / \mathrm{L} N$-2-hydroxyethylpiperazine- $N$ '-2-ethanesulfonic acid, $0.2 \mathrm{~g} / \mathrm{L} \mathrm{NaHCO}{ }_{3}$, streptomycin $(100 \mu \mathrm{g} / \mathrm{mL})$, and penicillin $(100 \mathrm{UI} / \mathrm{mL})$ as previously described. ${ }^{28,37}$ The initial inoculum was $5 \times 10^{4}$ cells $/ \mathrm{mL}$, which was subcultured every 2 days as described elsewhere ${ }^{28,29}$ and maintained in a log-phase growth. Cell detachment was performed with $2 \mathrm{~mL}$ of trypsin $0.05 \%(\mathrm{w} / \mathrm{v})$ for $2 \mathrm{~min}$.

\section{DC stimulation}

After the detachment, B16F10 cells were collected by centrifugation, washed, and suspended $\left(5.0 \times 10^{5}\right.$ cells $\left./ \mathrm{mL}\right)$ in PBS (pH 7.4) at 308 mOsm. The cellular suspensions were then distributed into a 24 -well culture plate $(2 \mathrm{~mL}$ of cell suspension/well). These wells were linked in series by filter paper bridges and fitted with platinum electrodes at their extremities, which were connected to a DC source (FA-3050 model; Instrutherm, Brazil). Control cells were presented with the same experimental conditions, except for the contact with the DC source (Figure 1). Following this approach, cell suspensions can be exposed directly to $\mathrm{CF}, \mathrm{AF}$, and $\mathrm{DC}$ 
Platinum electrodes

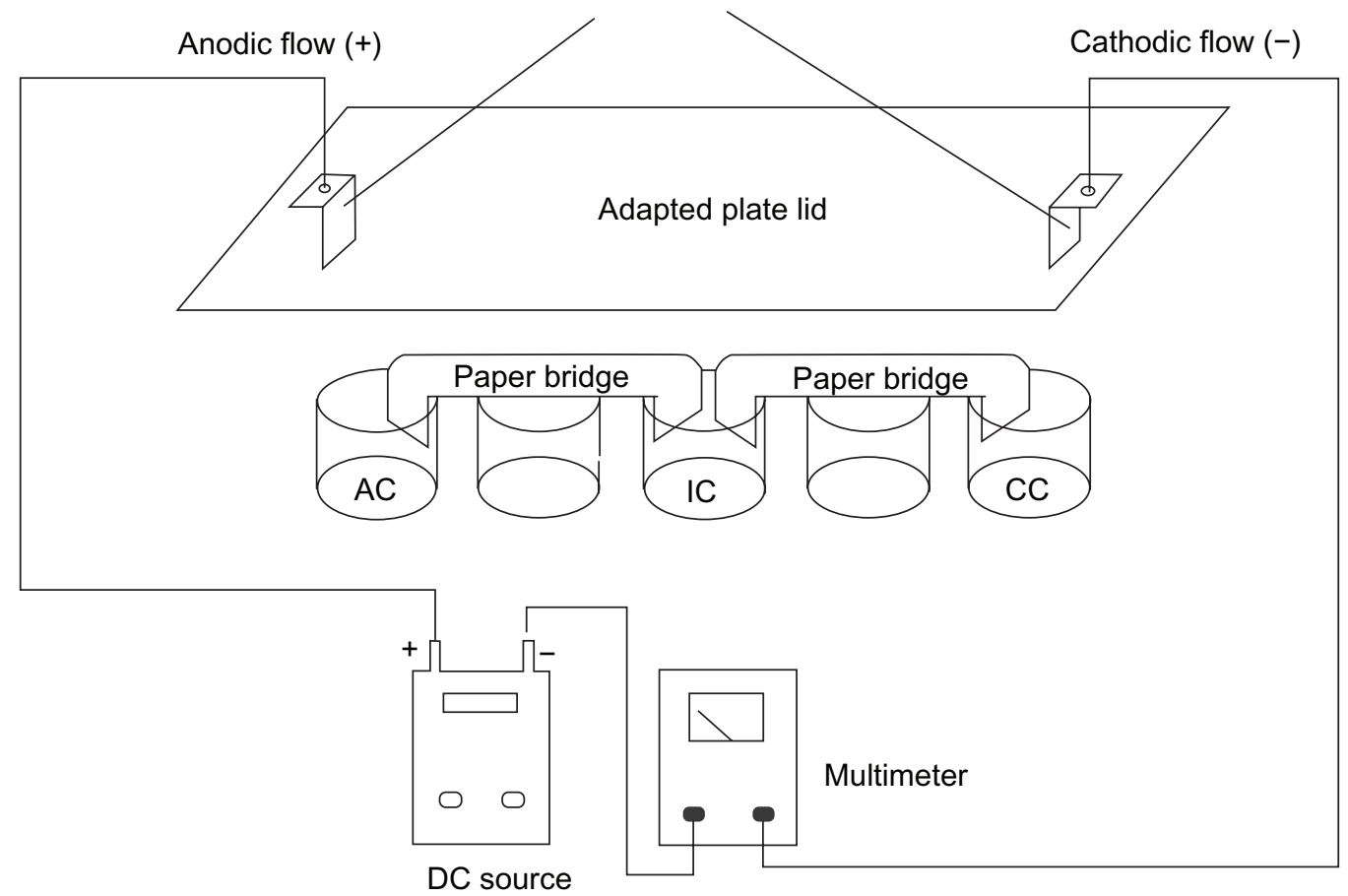

Figure I Schematic representation of the in vitro system used for DC treatment of BI6FIO cells. The cell suspensions are distributed over each individual well and connected to a positive pole (AF) and negative pole (CF). An intermediary well, namely electroionic flow (FEI), is connected to the other wells by filter paper bridges moistened with phosphate saline buffer. Platinum electrodes are inserted into the AF and CF poles, allowing the system to be connected to a DC source and an amperimeter to monitor DC intensity. This distribution permits the separate exposure of cells to cathodic and anodic reactions, and to the DC (FEl). Control cells are exposed to the same conditions, except for the use of DC. Internal volume of each well is $0.84 \mathrm{~cm}^{3}$. The distance between the electrodes was $8 \mathrm{~cm}$, and an electric field of approximately $2.5 \mathrm{~V} / \mathrm{cm}$ was generated.

without contact with the electrodes, namely electroionic flow (EIF) at $25^{\circ} \mathrm{C}$. The distance between the electrodes was $8 \mathrm{~cm}$, and an electric field of approximately $2.5 \mathrm{~V} / \mathrm{cm}$ was generated as a result. Cell suspensions were treated at room temperature with DC of $2 \mathrm{~mA}$, for 0 (control), 2, 4, 6, 8, and $10 \mathrm{~min}$, similar to the conditions previously used ${ }^{28-30,38}$ to assess cell viability. In all subsequent experiments, cells were treated for $6 \mathrm{~min}$, an intermediate period that was representative of the alterations in morphology and viability. The B16F10 cells were preincubated for $30 \mathrm{~min}$ with different electrolytic suspensions, such as PBS, PBS + $181.19 \mathrm{mg}$ of free L-tyrosine, PBS $+0.5 \mathrm{mg} / \mathrm{mL}$ of unloaded NPs, and PBS $+0.5 \mathrm{mg} / \mathrm{L}$ of L-tyrosine-loaded PCL NPs, which correspond to approximately $30 \mu \mathrm{g}$ of L-tyrosine. After incubation, DC treatment was performed for $6 \mathrm{~min}$, the electrolytic media was immediately removed, and all of the cells were washed twice with PBS. The cytotoxicity of the DC treatment was assessed by the MTT method after $24 \mathrm{~h}$ of incubation with DMEM supplemented with $10 \% \mathrm{FBS}$ as described below.

\section{Cell viability}

Cell viability was assessed by measuring the cellular mitochondrial activity by the MTT method. ${ }^{39,40}$ After DC treatment, cells were removed from the plate with trypsin (as described above) and resuspended in $2 \mathrm{~mL}$ of DMEM supplemented with FBS 10\%; $180 \mu \mathrm{L}$ of this cellular suspension was transferred to a 96-well microplate and incubated with $20 \mu \mathrm{L}$ of a $5-\mathrm{mg} / \mathrm{L}$ solution of tetrazolium reagent (MTT; Sigma-Aldrich) for $3 \mathrm{~h}$ at $37^{\circ} \mathrm{C}$. The supernatant was removed by centrifugation at $1100 \mathrm{rpm}$ for $7 \mathrm{~min}$ using the CT-6000R Cientec centrifuge (Piracicaba, Brazil). The formazan crystals were diluted in $200 \mu \mathrm{L}$ of pure dimethyl sulfoxide (Sigma-Aldrich), and the absorbance was read at $490 \mathrm{~nm}$ on a plate-reading spectrophotometer (thermoplate). Viability was calculated as the proportion of absorbance of each sample compared to that of the controls ( $\mathrm{Abs}_{\text {sample }}$ ' $\left.\mathrm{Abs}_{\text {control }}\right)$. This experiment was performed in quintuplicate.

\section{Cell growth}

To evaluate the influence of DC treatment on B16F10 growth, the cells were suspended in $2 \mathrm{~mL}$ of PBS $\left(10^{6}\right.$ cells $\left./ \mathrm{mL}\right)$ and treated for $6 \mathrm{~min}$. After DC treatment, the cells were washed in PBS, and the suspensions containing similar cell numbers were cultivated in a 24 -well plate in DMEM medium supplemented with FBS $10 \%$. Aliquots of $25 \mu \mathrm{L}$ of the cell suspensions were taken at 0,24 , and $48 \mathrm{~h}$, and 
the number of trypan blue-stained and -unstained cells was determined in a Neubauer chamber. For the quantitative assessment of growth inhibition, trypan blue-stained cells were not considered. ${ }^{28,29}$

\section{Results}

Table 1 shows the quantitative analysis of the encapsulation process and the characterization parameters of the NPs. The double emulsion technique yielded NPs with high homogeneity, as detected by the low PIs. PCL-loaded and -unloaded NPs showed the same morphological characteristics, as could be observed by transmission electron microscope, such as an elliptic form and regular borders, with sizes in the nanometer range (Figure 2). Indeed, the mean NPs diameters measured at the Zetasizer ranged from 244.90 to $269.00 \mathrm{~nm}$ (Table 1). The unloaded NPs showed significantly lower mean diameters when compared to those of the L-tyrosineloaded PCL NPs $(P<0.001)$. However, the size increase caused by amino acid insertion did not exceed $10 \%$ when compared to blank NPs.

The NP surface potential did not show significant alterations after L-tyrosine encapsulation or after AF exposure $(P>0.05)$ (Table 2$)$. The overall process yield was approximately $50 \%$ for both preparations, and the encapsulation efficiency reached approximately $30 \%$.

The release kinetics of L-tyrosine from loaded PCL NPs is shown in Figure 3. A burst release of approximately $80 \%$ of the total L-tyrosine was observed within the first $3 \mathrm{~h}$ of dissolution and subsequently followed by a drastic drop in the release rate. After 96 h, the NP content was virtually entirely released (data not shown).

Effects of various DC exposure times on B16F10 melanoma cell viability are shown in Figure 4A (immediately after exposure) and Figure 4B (24 h later). The AF and CF induced similar and statistically significant profiles of an immediate reduction in cell viability after four or more minutes of exposure, which was directly proportional to the stimulus time $(P<0.01)$. Twenty-four hours after DC exposure, the

Table I Process yield, drug encapsulation efficiency, mean diameter, and PI of blank and L-tyrosine-loaded PCL NPs $(n=3 \pm$ SD)

\begin{tabular}{llll}
\hline & $\begin{array}{l}\text { Process } \\
\text { yield }(\%)\end{array}$ & $\begin{array}{l}\text { Encapsulation efficiency } \\
(\mu \mathrm{g} / 1 \mathbf{0 0} \mathbf{~ m g} \text { of NP) }\end{array}$ & $\begin{array}{l}\text { Polydispersity } \\
\text { index }\end{array}$ \\
\hline Blank NP & $50 \pm 1$ & - & $0.075 \pm 0.02$ \\
L-Tyrosine- & $52 \pm 2$ & $30 \pm 1.2$ & $0.130 \pm 0.02$ \\
loaded PCL & & & \\
NPs & & & \\
\hline
\end{tabular}

Notes: Statistically significant difference between blank NP and L-tyrosine-loaded PCL NPs. *P $<0.001$. same viability profile was observed for the AF and $\mathrm{CF}$ in comparison to untreated control cells. The electroionic flow did not induce statistically significant changes in cell viability either immediately or $24 \mathrm{~h}$ after DC exposure $(P>0.05)$.

Cell proliferation was assessed 24 and $48 \mathrm{~h}$ after a 6-min anodic stimulation (Figure 5). The time required to reduce the B16F10 cell viability to approximately $60 \%$ was 6 min. For the cell proliferation experiment, the initial inoculum of control and treated cells was $1.33 \times 10^{5}$ and $1.08 \times 10^{5}$ cells, respectively. After $48 \mathrm{~h}$, the number of control cells increased from $1.33 \times 10^{5}$ to $2.55 \times 10^{5}$. However, after $24 \mathrm{~h}$ of treatment, using AF induced a significantly impaired growth of B16F10 cells; the number of cells dropped from $1.08 \times 10^{5}$ to $0.68 \times 10^{5}$, indicating a $54.7 \%$ reduction in cell number. This inhibition remained in this magnitude for $48 \mathrm{~h}$ of post-treatment, indicating that $\mathrm{B} 16 \mathrm{~F} 10$ cells were incapable of recovering their proliferation rates.

Effects of AF stimulation in the presence of free and encapsulated tyrosine on B16F10 viability are shown in Figure 6. This experiment showed that loaded- and unloadedPCL NPs did not exhibit any cytotoxic properties. However, using AF stimulation in association with tyrosine-loaded NPs induced a $40 \%$ decrease in cell viability immediately (data not shown) and $24 \mathrm{~h}$ after treatment, indicating that this combination has a promising antineoplastic potential. Additionally, the loading process enabled the use of a significantly lower amount of tyrosine in its encapsulated form when compared to its free form. In fact, the amount of tyrosine in the nanosystem was 6000-fold smaller and yet induced higher mortality rates (data not shown).

\section{Discussion}

Among the morphofunctional features of solid tumors are the abnormal function of the lymphatic vasculature, which causes fluid retention, and an increased permeability of blood vessel walls. Both of these characteristics lead to a higher retention of NPs in the tumor area when compared to that of normal tissues, resulting in a passive selectivity of the system. ${ }^{7}$ Thus, a small particle size, which is directly related to the technique of NPs obtention, is crucial for the desired tissue penetration. ${ }^{41}$

The size of DEEM-yielded NPs depends on many factors, such as stirring speed, solution viscosity, organic/ aqueous phase ratio, and PVA concentration in external aqueous phase..$^{42}$ In the present work, the use of sonication in conjunction with DEEM produced fine, nanometric-scaled, homogeneous pools of loaded- or unloaded-PCL NPs. The polydispersity values obtained were approximately 0.1 , 


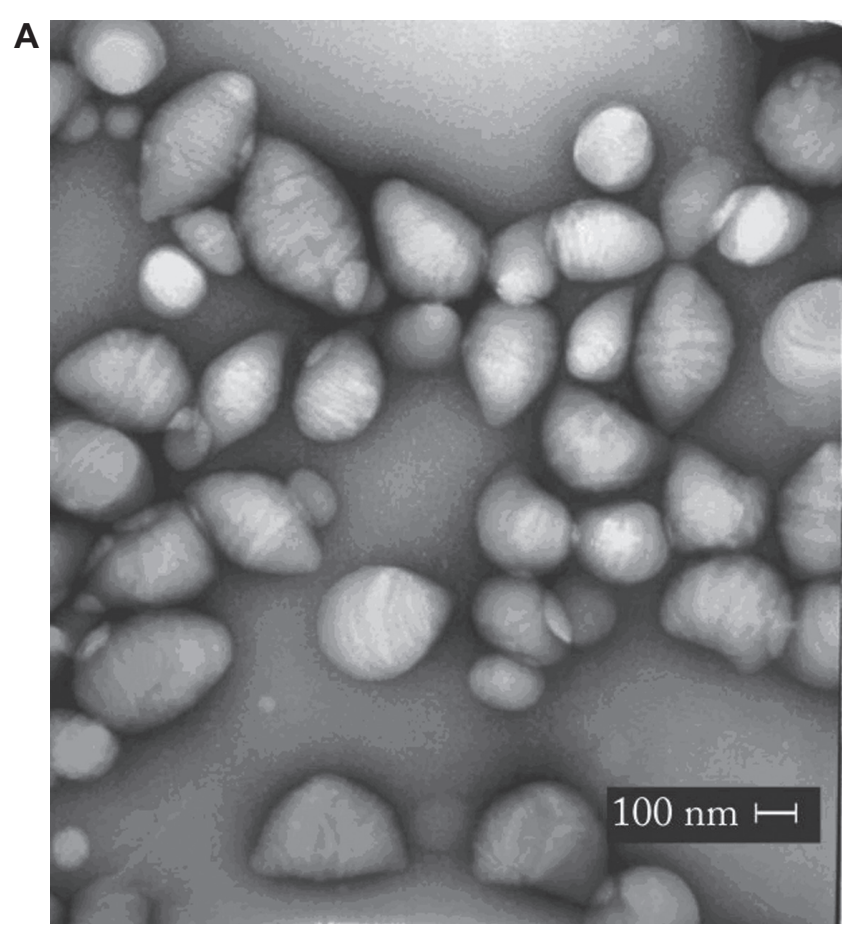

B

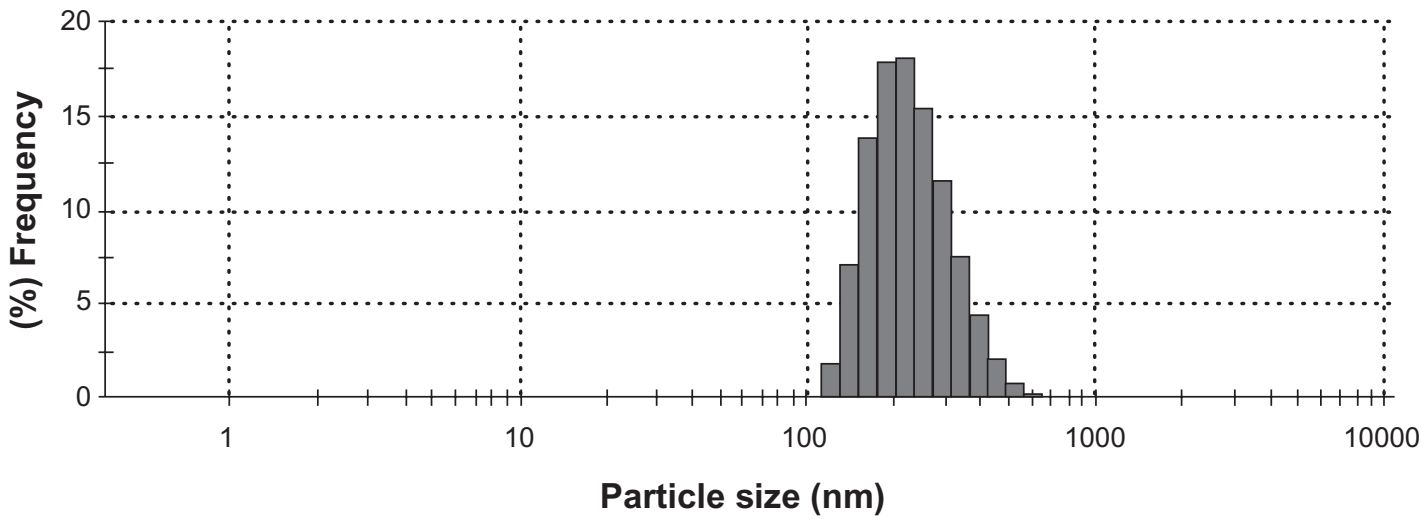

Figure 2 Morphological features and mean diameter of L-tyrosine-loaded PCL NPs. A) Transmission electron micrograph of PCL NPs loaded with L-tyrosine. Scale bar: I00 nm. B) Diameter distribution of PCL NPs loaded with L-tyrosine determined by photon correlation spectroscopy, showing that most NPs presented diameter in the nanometer scale. The experiments were done three times independently $(n=3)$.

indicating a monomodal distribution of particle size and a very high quality of preparation. ${ }^{43}$ Furthermore, the loading yield is comparable to other findings in the literature ${ }^{4,17}$ and is probably due to the low solubility of L-tyrosine in PBS aqueous phase. The surface charge of NPs can be characterized by the zeta potential, ${ }^{44}$ which reflects the electric potential

Table 2 Zeta potential analyses of blank and L-tyrosine-loaded PCL NPs

\begin{tabular}{lll}
\hline & $\begin{array}{l}\text { Before anodic } \\
\text { flow }\end{array}$ & $\begin{array}{l}\text { After 6 min of } \\
\text { anodic flow }\end{array}$ \\
\hline Blank NP & $-1.38 \pm 0.16$ & $-1.83 \pm 0.23$ \\
L-Tyrosine-loaded PCL NPs & $-1.76 \pm 0.19$ & $-2.10 \pm 0.25$ \\
\hline
\end{tabular}

Notes: The experiments were done three times independently $(n=3 \pm S D)$. of particles and is influenced by their chemical composition as well as the medium in which they are dispersed. ${ }^{2}$ To assess the influence of AF stimulation on the surface charge of the NPs, zeta potentials were also measured before and after a 6-min AF exposure for both preparations (loaded- and unloadedNPs). Indeed, the surface potentials became slightly more electronegative after $\mathrm{AF}$, although this increase did not prove to be statistically significant in our analysis $(P>0.05)$.

The majority of the amino acid content was released from loaded NPs within the first $3 \mathrm{~h}$ at a rate of $80 \%$. The release speed depends on the nature of both polymer and encapsulated molecule. ${ }^{3}$ The burst release effect observed in our system can be explained by molecules associated predominantly with the surface and the outer layers of the NP. ${ }^{34}$ 


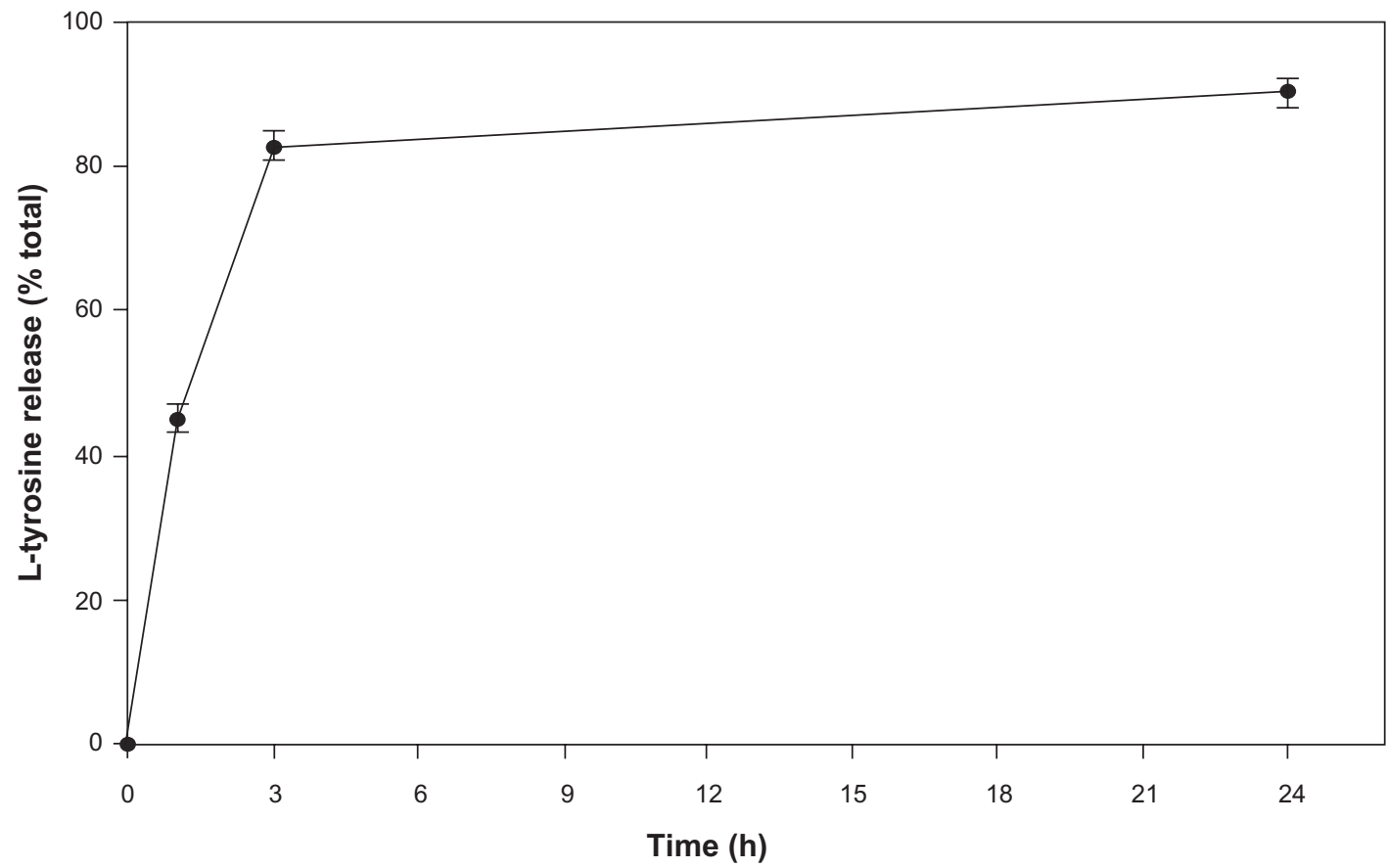

Figure 3 Release kinetics of L-tyrosine from PCL NPs in a period of $24 \mathrm{~h}$. The experiments were done three times independently $(n=3 \pm$ SD).

The sustained release is due to the semicrystalline structure of PCL NPs and the pores formed in its polymeric matrix during the encapsulation process. ${ }^{18}$ Once in an aqueous environment, the PCL NP matrix slowly undergoes erosion, allowing penetration of water into its structure and the outward diffusion of L-tyrosine.

This in vitro release study determined that a preincubation time of $30 \mathrm{~min}$ was adequate to ensure the delivery of a significant amount of L-tyrosine. In addition, exposure of B16F10 cells to a 6-min AF treatment in PBS resulted in an immediate cell death of approximately $50 \%$ and significant impairment of growth recovery after $24 \mathrm{~h}$. These conditions have been defined as the most suitable parameters for comparing the different experimental groups.

DC is a physical agent capable of destroying different kinds of tumor cells, characterizing a tumor therapy (EChT). This treatment is noted for its great effectiveness, minimal invasiveness, local effect, and low cost. ${ }^{24-26}$ The principal tumor damage induced by DC has been attributed to the formation of electrolysis products, which were capable of killing the tumor cells. ${ }^{21}$ Our research group has detected the effects of $\mathrm{pH}$ acidification and alkalinization induced by $\mathrm{AF}$ and $\mathrm{CF}$ on different tumor cell lines. ${ }^{28-30,38}$ However, in these studies, tumor death was not only attributed exclusively to the electrolysis damage, but also to the oxidant species generated by the $\mathrm{AF}^{29,30}$ In fact, the acidification of the AFtreated medium could not be held responsible for the cell killing, as the $\mathrm{pH}$ variation induced by anodic reactions is not significant (6.5 after 10 min of stimulation). ${ }^{30}$ Besides, when the $\mathrm{pH}$ was artificially mimetized by the addition of $\mathrm{HCl}$ drops, cell viability was not diminished at equivalent rates as detected by AF generated by DC source, suggesting the role of other electrolysis products, such as reactive chlorine and oxygen species, in tumor killing. ${ }^{30}$

It is common knowledge that DC can both change surface cell receptors and also modify cell membrane permeability. ${ }^{28,29,45}$ In fact, this latter property is used therapeutically to ease drug penetration into tumor cells, a combined technique known as electrochemotherapy. ${ }^{46-48}$ In the present study, NPs were produced with PCL; this polymer has a negative electrokinetic potential, probably due to the presence of some residual functional groups with negative charges on the monomer employed in PCL polymerization. ${ }^{44} \mathrm{After}$ the loading process and the anodic stimulation, we detected a modification of the zeta potential, but the NPs remained negatively charged. As shown in Table 2, these values varied between -1.38 and $-2.10 \mathrm{mV}$. Thus, the increase in the cytotoxic effect detected from using tyrosine-loaded NPs in conjunction with AF is probably not due to changes in electrostatic interactions. The use of NPs containing amino acids guaranteed a constant production and/or delivery of chloramines to tumoral cells, which is reflected in increased cellular mortality. In fact, using DC in conjunction with L-tyrosine-loaded PCL 
A

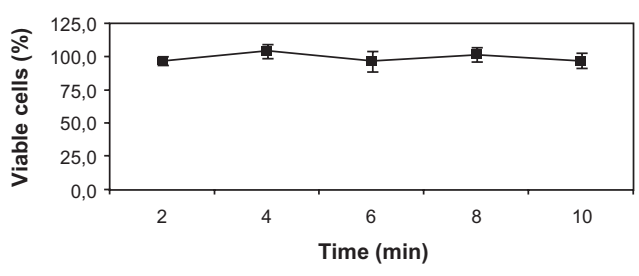

Electroionic flow

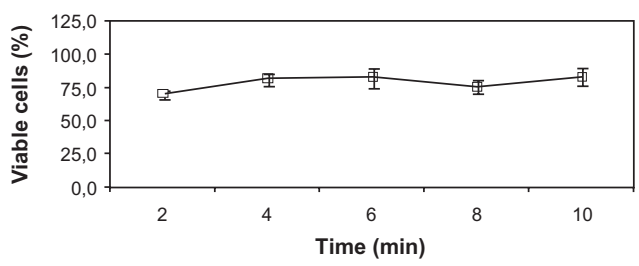

B

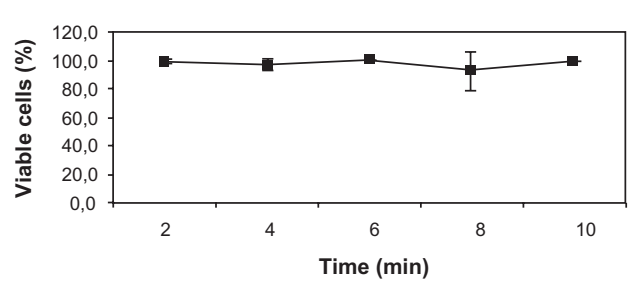

Electroionic flow

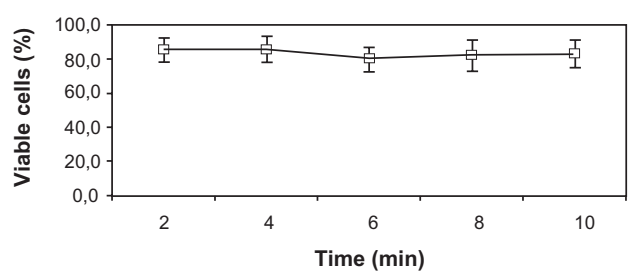

Anodic flow

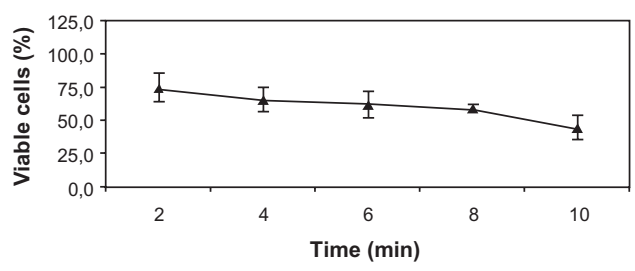

Cathodic flow

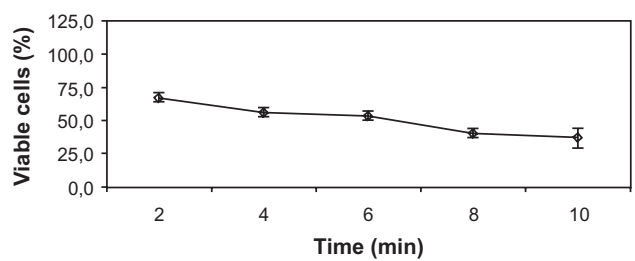

Anodic flow

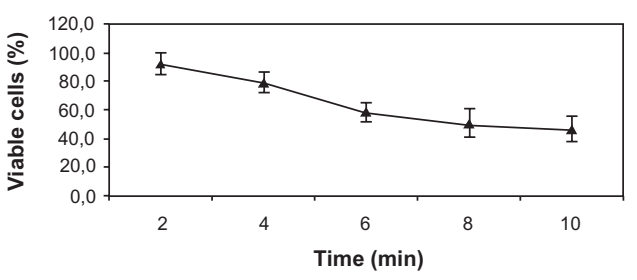

Cathodic flow

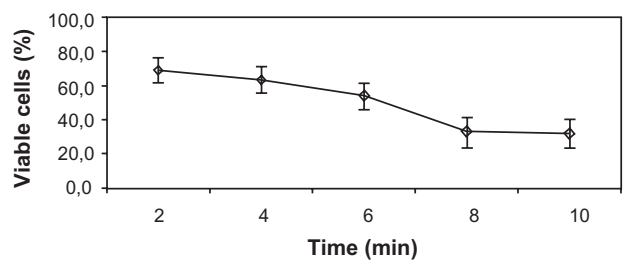

Figure 4 Kinetics of trypan blue incorporation by both treated and untreated BI6FI0 cells. A) BI6FI0 cells were treated with 2 mA of DC for periods varying from 0 to $10 \mathrm{~min}$ and their viability assayed immediately by the trypan blue method. Black squares represent the viability of control cells ( $\mathbf{m})$, and the open symbols represent the cells treated by the $\mathrm{CF}(\vartheta), \operatorname{AF}(\boldsymbol{\Delta})$, and electroionic flow $(\square)$. Anodic and cathodic stimuli induced significant differences in the BI6FI0 viability when compared to untreated cells $(P<0.01)$, except for the AF stimulus of 2 min. Besides, the electroionic flow stimuli did not induce any changes in cell viability $(P>0.05)$. B) BI6FI0 cells were treated for periods varying from 0 to $10 \mathrm{~min}$, and their viability was assayed by the trypan blue method $24 \mathrm{~h}$ after the treatment. Black squares represent the viability of control cells ( $\square)$, and the open symbols represent the cells treated by the $\operatorname{CF}(\vartheta), \operatorname{AF}(\mathbf{\Delta})$, and electroionic flow $(\square)$. This graph shows that the cell viability was not recovered, except for the cells treated for 4 min with the AF stimulus. As detected immediately after treatment, the electroionic flow stimuli did not induce any changes in cell viability $(P>0.05)$.

NPs reduced B16F10 viability to approximately 50\%; this reduction in viability probably resulted from chloramines generated within the electrolytic medium, which led to cell destruction by apoptosis..$^{31,49,50}$ Interestingly, the total amount of encapsulated amino acid tested was 6000-fold lower than that used in the free amino acid experiment (data not shown), which justified the use of NPs systems to improve the cytotoxicity of DC.

Additionally, necrotic cell death induced by DC is an undesirable aspect of this therapy and seems to be directly associated to DC intensity, polarity, and time of exposure. ${ }^{30}$ This is an important aspect that cannot be neglected in EChT, due to the triggering of inflammatory response as well as the disarray of tumor structure, which may lead to a systemic spread of tumor cells. The constant release of chloramines obtained from the interaction of amino groups present in the tyrosine and the chlorine species generated by DC is a possible strategy to promote cell death by apoptosis rather than necrosis, using milder DC intensity/time of exposure regimens. Besides, EChT application is most useful in the treatment of solid tumors ${ }^{51}$ in which different electrode configurations and DC intensities are applied. This procedure is not standardized in the literature, yet it has presented good results in making inoperable tumors into operable ones ${ }^{52,53}$ and in destroying tumor mass by necrosis. ${ }^{54}$ 


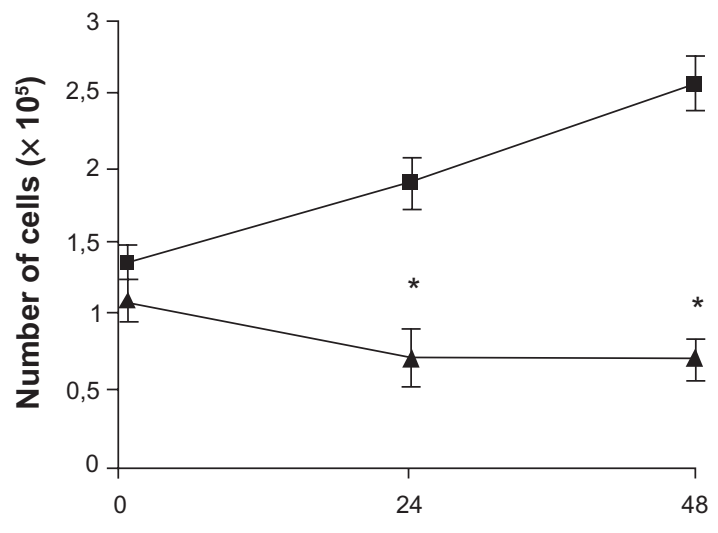

Time of cultivation pos-DC treatment (h)

Figure 5 Treatment of BI6FIO cells with DC inhibits cell proliferation. Cells were treated with $2 \mathrm{~mA}$ of $\mathrm{AF}$ for $6 \mathrm{~min}(\boldsymbol{\Delta})$ and inoculated into fresh media. The number of cells treated and untreated ( $\mathbf{\square}$ ) was quantified by trypan blue dye after $24 \mathrm{~h}$ and $48 \mathrm{~h}$, considering only the cells that were not permeable to the dye (viable cells). The proliferation rate of treated cells was $54.7 \%$ lower than the untreated cells. Results of five independent experiments expressed as mean \pm SD are shown.

The use of nanotechnology and EChT was first applied in $\mathrm{C} 56 \mathrm{BL} / 6 \mathrm{Y}$ black mice previously inoculated with B16F10 cells with the aim to verify the possibility of translating the in vitro model to treatment of in situ melanoma. In this model, the L-tyrosine-loaded PCL NPs must be injected into the solid tumor to avoid NP leakage to normal cells, protecting these cells from DC damage. The preliminary results obtained showed that the association of L-tyrosine-loaded PCL NPs with DC induced an almost total destruction of these cancer cells after $48 \mathrm{~h}$ of treatment, as detected by optical and electronic microscopy analyses, with no side effects in important organs, such as liver and breast. The safety of this treatment for normal cells is probably attributed to the use of a biodegradable polymer (PCL) as loader of tyrosine, which is a natural amino acid present in living animals, therefore, avoiding adverse effects common in traditional anticancer treatment. These results are still awaiting confirmation, and there are many challenges that need to be faced to permit the translatability of in vitro results to in vivo models. Before we can consider the use of L-tyrosine-loaded PCL NPs associated with DC for in situ cancer treatment, we must face challenges, such as the need for a higher number of animals to be studied, inoculation of different kinds of tumors, and different electrode configurations and DC intensities among others.

\section{Conclusion}

Nanotechnology is generating new perspectives in a number of scientific fields. Its applications in cancer medicine are currently being investigated with very promising results in an in vitro model. The never-before-described use of the combination of this technology with EChT aims to make DC tumor treatment even more efficient and opens the door for a new cancer therapeutic approach. One of the problems associated with EChT is the occurrence of necrosis, which seems to be directly proportional to the DC intensity applied. The use of nanotechnology in conjunction with DC may promote apoptotic cell death over necrotic damage, especially when the AF is applied in the presence of amino acid-loaded NPs. In fact, this hypothesis is being tested in $\mathrm{C} 56 \mathrm{BL} / 6 \mathrm{Y}$ black mice previously inoculated with $\mathrm{B} 16 \mathrm{~F} 10$ cells, and the results obtained so far, however preliminary, are quite successful, without any side effects commonly found in traditional anticancer treatment, probably due to the use of a biodegradable polymer loaded with a natural amino acid.

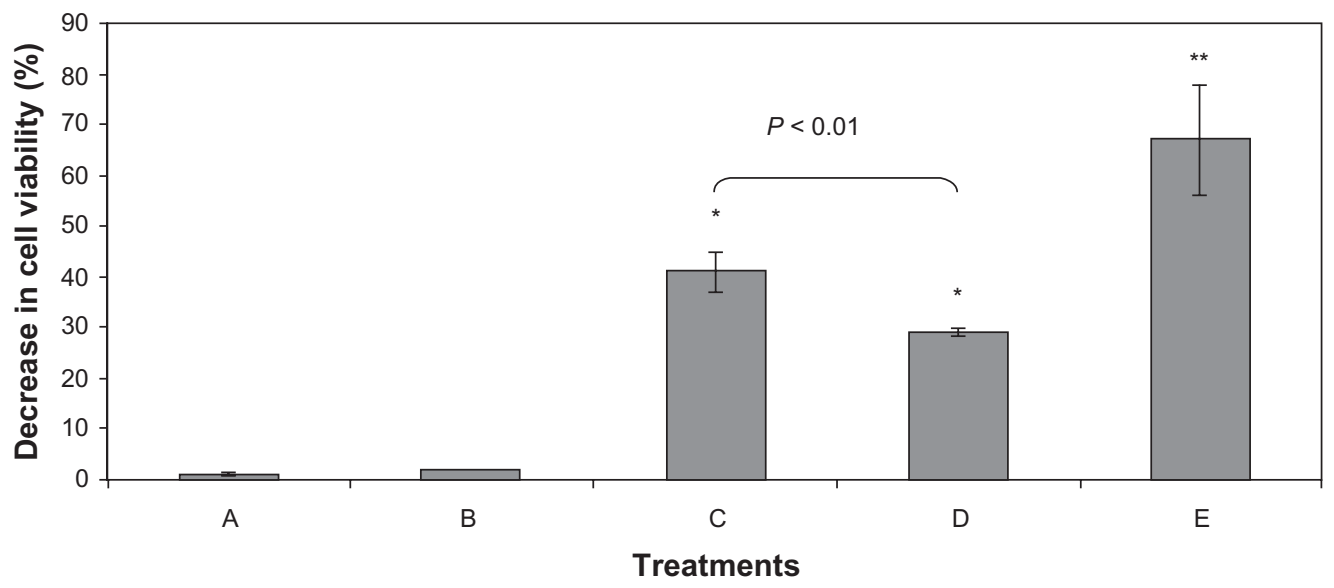

Figure 6 Decrease in the BI6FI0 viability induced by different experimental conditions measured by MTT assay. Cells were treated with A) L-tyrosine-loaded PCL NPs, B) unloaded NPs, C) 6 min of AF, D) unloaded NPs plus AF, and E) L-tyrosine-loaded PCL NPs plus AF. The percentage of viability decrease was determined immediately (data not shown) and $24 \mathrm{~h}$ after treatment. The major cell viability decrease (around 60\%) was obtained when the L-tyrosine-loaded PCL NPs were associated with AF. Results of three independent experiments expressed as mean \pm SD are shown.

Notes: "Significantly different from control with $P<0.05$. 


\section{Acknowledgments}

We thank Dr Marcio Lourenço Rodrigues for critical reading of the manuscript. This work was supported by Conselho Nacional de Desenvolvimento Científico e Tecnológico (CNPq), Fundação de Amparo à Pesquisa no Estado do Rio de Janeiro (FAPERJ), and Fundação José Bonifácio (FUJB).

\section{Disclosure}

The authors report no conflicts of interest in this work.

\section{References}

1. Mora-Huertas CE, Fessi H, Elaissari A. Polymer-based nanocapsules for drug delivery. Int J Pharm. 2010;385(1-2):113-142.

2. Singh R, Lillard JW Jr. Nanoparticle-based targeted drug delivery. Exp Mol Pathol. 2009;86(3):215-223.

3. Soppimath KS, Aminabhavi TM, Kulkarni AR, Rudzinski WE. Biodegradable polymeric nanoparticles as drug delivery devices. J Control Release. 2001;70(1-2):1-20.

4. Hans ML, Lowman AM. Biodegradable nanoparticles for drug delivery and targeting. Curr Opin Solid State Mater Sci. 2002;6(4): 319-327.

5. Feng S, Huang G. Effects of emulsifiers on the controlled release of paclitaxel (Taxol) from nanospheres of biodegradable polymers. J Control Release. 2001;71(1):53-69.

6. Farokhzad OC, Cheng J, Teply BA, et al. Targeted nanoparticle-aptamer bioconjugates for cancer chemotherapy in vivo. Proc Natl Acad Sci U S A. 2006;103(16):6315-6320.

7. Alexis F, Rhee JW, Richie JP, Radovic-Moreno AF, Langer R, Farokhzad OC. New frontiers in nanotechnology for cancer treatment. Urol Oncol. 2008;26(1):74-85.

8. Chawla JS, Amiji MM. Biodegradable poly(epsilon-caprolactone) nanoparticles for tumor-targeted delivery of tamoxifen. Int J Pharm. 2002;249(1-2):127-138.

9. Espuelas M, Legrand P, Campanero M, et al. Polymeric carriers for amphotericin B: in vitro activity, toxicity and therapeutic efficacy against systemic candidiasis in neutropenic mice. J Antimicrob Chemother. 2003;52(3):419-427.

10. Sinha VR, Bansal K, Kaushik R, Kumria R, Trehan A. Poly-epsiloncaprolactone microspheres and nanospheres: an overview. Int J Pharm. 2004;278(1):1-23.

11. Park SJ, Lee YM, Hong SK. Release behaviors of porous poly(butylene succinate)/poly(epsilon-caprolactone) microcapsules containing indomethacin. Colloids Surf B Biointerfaces. 2006;47(2):211-215.

12. Zili Z, Sfar S, Fessi H. Preparation and characterization of poly-epsiloncaprolactone nanoparticles containing griseofulvin. Int J Pharm. 2005; 294(1-2):261-267.

13. Shenoy DB, Amiji MM. Poly(ethylene oxide)-modified poly(epsiloncaprolactone) nanoparticles for targeted delivery of tamoxifen in breast cancer. Int J Pharm. 2005;293(1-2):261-270.

14. Singh J, Pandit S, Bramwell VW, Alpar HO. Diphtheria toxoid loaded poly-(epsilon-caprolactone) nanoparticles as mucosal vaccine delivery systems. Methods. 2006;38(2):96-105.

15. Yang J, Park SB, Yoon HG, Huh YM, Haam S. Preparation of poly epsilon-caprolactone nanoparticles containing magnetite for magnetic drug carrier. Int J Pharm. 2006;324(2):185-190.

16. Yenice I, Mocan M, Palaska E, et al. Hyaluronic acid coated polyepsilon-caprolactone nanospheres deliver high concentrations of cyclosporine A into the cornea. Exp Eye Res. 2008;87(3):162-167.

17. Benoit MA, Baras B, Gillard J. Preparation and characterization of protein-loaded poly(epsilon-caprolactone) microparticles for oral vaccine delivery. Int J Pharm. 1999;184(1):73-84.

18. Berman B, Perez O, Zell D. Immunological strategies to fight skin cancer. Skin Therapy Lett. 2006;11(5):1-7.
19. Tewes F, Munnier E, Antoon B, et al. Comparative study of doxorubicinloaded poly(lactide-co-glycolide) nanoparticles prepared by single and double emulsion methods. Eur J Pharm Biopharm. 2007;66(3): 488-492.

20. Miklavcic D, Jarm T, Cemazar M, et al. Tumor treatment by direct electric current. Tumor perfusion changes. Bioelectrochem Bioenerg. 1997;43:253-256.

21. Nilsson E, von Euler H, Berendson J, et al. Electrochemical treatment of tumours. Bioelectrochemistry. 2000;51(1):1-11.

22. Ciria HC, Quevedo MS, Cabrales LB, et al. Antitumor effectiveness of different amounts of electrical charge in Ehrlich and fibrosarcoma Sa-37 tumors. BMC Cancer. 2004;4:87.

23. Nordenström BEW. Biologically closed electric circuits: activation of vascular interstitial closed electric circuits for treatment of inoperable cancers. Bioelectromagnetics. 1984;3:137-153.

24. Nordenström BE. Electrochemical treatment of cancer. I: Variable response to anodic and cathodic fields. Am J Clin Oncol. 1989;12(6):530-536.

25. Nordenström BE. Survey of mechanisms in electrochemical treatment (ECT) of cancer. Eur J Surg Suppl. 1994;(574):93-109.

26. Nordenström BEW. Preliminary clinical trials of electrophoretic ionization in the treatment of malignant tumors. IRCS Med Sci Biomed Technol. 1978;6:537-540.

27. Nordenström BE, Eksborg S, Beving H. Electrochemical treatment of cancer. II: Effect of electrophoretic influence on adriamycin. Am J Clin Oncol. 1990;13(1):75-88

28. Holandino C, Veiga VF, Rodrigues ML, Morales MM, Capella MA, Alviano CS. Direct current decreases cell viability but not P-glycoprotein expression and function in human multidrug resistant leukemic cells. Bioelectromagnetics. 2001;22(7):470-478.

29. Veiga V, Holandino C, Rodrigues M, Capella M, Menezes S, Alviano C. Cellular damage and altered carbohydrate expression in P815 tumor cells induced by direct electric current: an in vitro analysis. Bioelectromagnetics. 2000;21(8):597-607.

30. Veiga VF, Nimrichter L, Teixeira CA, et al. Exposure of human leukemic cells to direct electric current: generation of toxic compounds inducing cell death by different mechanisms. Cell Biochem Biophys. 2005;42(1):61-74.

31. Wagner BA, Britigan BE, Reszka KJ, McCormick ML, Burns CP. Hydrogen peroxide-induced apoptosis of HL-60 human leukemia cells is mediated by the oxidants hypochlorous acid and chloramines. Arch Biochem Biophys. 2002;401(2):223-234.

32. Englert RP, Shacter E. Distinct modes of cell death induced by different reactive oxygen species: amino acyl chloramines mediate hypochlorous acid-induced apoptosis. J Biol Chem. 2002;277(23):20518-20526.

33. Santoyo S, Ga de Jalón E, Ygartua P, Renedo M, Blanco-Príeto M. Optimization of topical cidofovir penetration using microparticles. Int J Pharm. 2002;242(1-2):107-113.

34. Hasan AS, Socha M, Lamprecht A, et al. Effect of the microencapsulation of nanoparticles on the reduction of burst release. Int J Pharm. 2007;344(1-2):53-61.

35. Ricci-Júnior E, Marchetti JM. Zinc(II) phthalocyanine loaded PLGA nanoparticles for photodynamic therapy use. Int J Pharm. 2006; 310(1-2):187-195.

36. Fonseca ME, Frimer N, Mendonça RE, Couceiro JN, Machado RD. A combined staining technique developed for virus particle observation in the electron microscope. Rev Bras Biol. 1984;44(1):37-40.

37. Freshney NW, Goonesekera SD, Feig LA. Activation of the exchange factor Ras-GRF by calcium requires an intact Dbl homology domain. FEBS Lett. 1997;407(1):111-115.

38. Holandino C, Veiga VF, Capella MM, Menezes S, Alviano CS. Damage induction by direct electric current in tumoural target cells. Indian J Exp Biol. 2000;38(6):554-558.

39. Mosmann T. Rapid colorimetric assay for cellular growth and survival: application to proliferation and cytotoxicity assays. J Immunol Methods. 1983;65(1-2):55-63.

40. Meira DD, Marinho-Carvalho MM, Teixeira CA, et al. Clotrimazole decreases human breast cancer cells viability through alterations in cytoskeleton-associated glycolytic enzymes. Mol Genet Metab. 2005; 84(4):354-362. 
41. Kong G, Braun RD, Dewhirst MW. Hyperthermia enables tumorspecific nanoparticle delivery: effect of particle size. Cancer Res. 2000; 60(16):4440-4445.

42. Yang YY, Chung TS, Ng NP. Morphology, drug distribution, and in vitro release profiles of biodegradable polymeric microspheres containing protein fabricated by double-emulsion solvent extraction/ evaporation method. Biomaterials. 2001;22(3):231-241.

43. Graf A, Ablinger E, Peters S, Zimmer A, Hook S, Rades T. Microemulsions containing lecithin and sugar-based surfactants: nanoparticle templates for delivery of proteins and peptides. Int J Pharm. 2008;350(1-2):351-360.

44. Lince F, Marchisio DL, Barresi AA. Strategies to control the particle size distribution of poly-epsilon-caprolactone nanoparticles for pharmaceutical applications. J Colloid Interface Sci. 2008;322(2): 505-515.

45. Holandino C, Capella MA, Angluster J, Silva-Filho FC, Menezes S, Alviano CS. Cell surface alterations induced by methylene blue and direct electric current in Escherichia coli. Indian J Biochem Biophys. 1998;35(5):284-290.

46. Janigro D, Perju C, Fazio V, et al. Alternating current electrical stimulation enhanced chemotherapy: a novel strategy to bypass multidrug resistance in tumor cells. BMC Cancer. 2006;6:72.

47. Colombo L, González G, Marshall G, et al. Ion transport in tumors under electrochemical treatment: in vivo, in vitro and in silico modeling. Bioelectrochemistry. 2007;71(2):223-232.
48. Sersa G, Miklavcic D, Cemazar M, Rudolf Z, Pucihar G, Snoj M. Electrochemotherapy in treatment of tumours. Eur J Surg Oncol. 2008; 34(2):232-240.

49. Peskin AV, Winterbourn CC. Histamine chloramine reactivity with thiol compounds, ascorbate, and methionine and with intracellular glutathione. Free Radic Biol Med. 2003;35(10):1252-1260.

50. Klamt F, Shacter E. Taurine chloramine, an oxidant derived from neutrophils, induces apoptosis in human B lymphoma cells through mitochondrial damage. J Biol Chem. 2005;280(22): 21346-21352.

51. Salzberg M, Kirson E, Palti Y, Rochlitz C. A pilot study with very low-intensity, intermediate-frequency electric fields in patients with locally advanced and/or metastatic solid tumors. Onkologie. 2008;31: 362-365.

52. Griffin DT, Dodd NJ, Moore JV, Pullan BR, Taylor TV. The effects of low level direct current therapy on a preclinical mammary carcinoma: tumor regression and systemic biochemical sequelae. $\mathrm{Br} J$ Cancer. 1994;69(5):875-878.

53. Fosh BG, Finch JG, Lea M, et al. Use of electrolysis as an adjunct to liver resection. Br J Surg. 2002;89(8):999-1002.

54. Plesnicar A, Sersa G, Vodovnik L, Jancar J, Zaletel-Kragelj L, Plesnicar S. Electric treatment of human melanoma skin lesions with low level direct electric current: an assessment of clinical experience following a preliminary study in five patients. Eur J Surg Suppl. 1994;(574): 45-49.
International Journal of Nanomedicine

\section{Publish your work in this journal}

The International Journal of Nanomedicine is an international, peerreviewed journal focusing on the application of nanotechnology in diagnostics, therapeutics, and drug delivery systems throughout the biomedical field. This journal is indexed on PubMed Central,

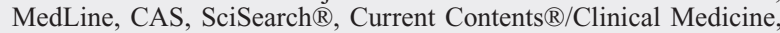

\section{Dovepress}

Journal Citation Reports/Science Edition, EMBase, Scopus and the Elsevier Bibliographic databases. The manuscript management system is completely online and includes a very quick and fair peer-review system, which is all easy to use. Visit http://www.dovepress.com/ testimonials.php to read real quotes from published authors. 